\title{
Inflation Illusion and Stock Prices
}

\section{Citation}

Campbell, John Y., and Tuomo Vuolteenaho. 2004. Inflation illusion and stock prices. American Economic Review 94, no. 2: 19-23.

\section{Published Version}

http://dx.doi.org/10.1257/0002828041301533

\section{Permanent link}

http://nrs.harvard.edu/urn-3:HUL.InstRepos:3196090

\section{Terms of Use}

This article was downloaded from Harvard University's DASH repository, and is made available under the terms and conditions applicable to Other Posted Material, as set forth at http:// nrs.harvard.edu/urn-3:HUL.InstRepos:dash.current.terms-of-use\#LAA

\section{Share Your Story}

The Harvard community has made this article openly available.

Please share how this access benefits you. Submit a story.

Accessibility 
NBER WORKING PAPER SERIES

\title{
INFLATION ILLUSION AND STOCK PRICES
}

\author{
John Y. Campbell \\ Tuomo Vuolteenaho \\ Working Paper 10263 \\ http://www.nber.org/papers/w10263
NATIONAL BUREAU OF ECONOMIC RESEARCH 1050 Massachusetts Avenue
Cambridge, MA 02138
January 2004

We would like to thank Cliff Asness for his helpful comments. This material is based upon work supported by the National Science Foundation under Grant No. 0214061 to Campbell. The views expressed herein are those of the authors and not necessarily those of the National Bureau of Economic Research.

(C)2004 by John Y. Campbell and Tuomo Vuolteenaho. All rights reserved. Short sections of text, not to exceed two paragraphs, may be quoted without explicit permission provided that full credit, including (C) notice, is given to the source. 
Inflation Illusion and Stock Prices

John Y. Campbell and Tuomo Vuolteenaho

NBER Working Paper No. 10263

January 2004

JEL No. G12, G14, N22

\section{ABSTRACT}

We empirically decompose the S\&P 500's dividend yield into (1) a rational forecast of long-run real dividend growth, (2) the subjectively expected risk premium, and (3) residual mispricing attributed to the market's forecast of dividend growth deviating from the rational forecast. Modigliani and Cohn's (1979) hypothesis and the persistent use of the "Fed model" by Wall Street suggest that the stock market incorrectly extrapolates past nominal growth rates without taking into account the impact of time-varying inflation. Consistent with the Modigliani-Cohn hypothesis, we find that the level of inflation explains almost $80 \%$ of the time-series variation in stock-market mispricing.

John Y. Campbell

Department of Economics

Harvard University

Littauer Center 213

Cambridge, MA 02138

and NBER

john_campbell@harvard.edu

Tuomo Vuolteenaho

Harvard University

Department of Economics

Littauer Center

Cambridge, MA 02138

and NBER

t_vuolteenaho@harvard.edu 


\section{The "Fed model" of equity valuation}

The influence of the macroeconomy on the stock market is a subject of enduring importance and fascination to academics, investment professionals, and monetary policymakers. Academics have devoted much of their effort to models that link stock prices to consumption through the first-order conditions of individual investors. Most investment professionals have adopted a radically different perspective. The leading practitioner model of equity valuation, the so-called "Fed model," relates the yield on stocks (as measured by the ratio of dividends or earnings to stock prices) to the yield on nominal Treasury bonds. The idea is that stocks and bonds compete for space in investors' portfolios. If the yield on bonds rises, then the yield on stocks must also rise to maintain the competitiveness of stocks. The model is often augmented to include a measure of the relative risk premium on stocks versus bonds, for example, the historical relative volatility of the returns on these two asset classes. Practitioners argue that the bond yield plus a risk premium defines a "normal" yield on stocks, and that the actual stock yield tends to revert to this normal yield. If the measured stock yield exceeds the normal yield defined by the Fed model, then stocks are attractively priced; if the measured yield falls below the normal yield, then stocks are overpriced.

Historically, the major influence on nominal bond yields has been the rate of inflation. Thus the Fed model implies that stock yields are highly correlated with inflation. In the late 1990's practitioners often argued that falling stock yields, and rising stock prices, were justified by declining inflation.

As pointed out by Asness (2000, 2003), the Fed model has been quite successful as an empirical description of stock prices. Most notably, the model describes the rise in stock yields, along with inflation, during the 1970's and early 1980's, and the decline in stock yields during the past 20 years. Of course, movements in stock and bond prices are highly persistent, and so it is desirable to evaluate the empirical performance of the Fed model over a longer period. In Table 1 we use a series of regressions to illustrate the performance of the model in the period 1927-2002. Each regression has a measure of the stock yield as the dependent variable, and proxies for the risk premium and the nominal discount rate as the independent variables. Our basic measure of the stock yield is the dividend-price ratio, but we also consider the earnings-price ratio, smoothed by averaging earnings over five years. Our first proxy for the risk premium is a cross-sectional beta premium within the stock market, calculated by Polk, Thompson, and Vuolteenaho (2003) as the rank-order correlation

of stock-level yield measures with the stock's CAPM beta. When this correlation 
is high, it implies that market participants expect a high reward for bearing market risk since riskier (higher-beta) stocks are much cheaper than less risky stocks. Our second risk premium proxy is the historical volatility of excess stock returns relative to that of nominal bonds, a measure previously employed by, e.g., Asness (2003). To measure the nominal discount rate we use either the average historical rate of inflation, calculated as an exponentially declining moving average of past monthly inflation rates, or the nominal yield on ten-year Treasury bonds.

The benchmark regression in the first row of Table 1 explains $49 \%$ of the variation in the dividend-price ratio using the cross-sectional risk premium and the historical inflation rate. Both variables are strongly statistically significant. Beyond the statistical significance, the fit of this regression is illustrated in Figure 1. Here the triangles are the demeaned dividend-price ratio, the solid line is the contribution of the cross-sectional risk premium to the fit of the regression (the multivariate regression coefficient times the risk premium), and the dashed line is the contribution of the inflation rate to the fit of the regression. The figure shows that much of the volatile movement of the dividend-price ratio during the 1930's and 1940's was related to volatile movement of the cross-sectional risk premium. At the bottom of the Great Depression, this explained the high level of the dividend-price ratio despite the presence of deflation, which our estimated model suggests should have supported stock prices. As inflation rose during the late 1930's and 1940's, its negative influence on stock prices was outweighted by the declining risk premium. In the postwar period the cross-sectional risk premium generally trended downward, reaching a low point in the early 1980's. The inflation rate rose steadily during the 1960's and 1970's, and accounts for the high dividend-price ratio (depressed stock prices) of the early 1980's. During the later 1980's and 1990's, the dividend-price ratio was driven downwards both by a declining cross-sectional equity premium and by a declining inflation rate, although the run-up in stock prices during the 1990's was too extreme to be fully explained by our two variables.

Alternative specifications are reported in subsequent rows of Table 1. Row two uses the five-year smoothed earnings yield rather than the dividend yield; this change reduces the $R^{2}$ substantially, but has little effect on the estimated coefficients. A regression that substitutes relative volatility for the cross-sectional risk premium (row three) has a very similar fit to the benchmark regression. Substituting the nominal bond yield for historical inflation reduces the fit somewhat if the risk measure is the cross-sectional risk premium (row four), but not if the risk measure is relative volatility (row five). 


\section{Interpreting the Fed model}

Despite the empirical success of the Fed model as a behavioral description of stock prices, there is a serious difficulty with this model as a rational explanation of stock prices (Modigliani and Cohn 1979, Ritter and Warr 2002, Asness 2000, 2003). To understand the difficulty, consider the classic "Gordon growth model" (Williams 1938, Gordon 1962) that expresses the dividend-price ratio in steady state as

$$
\frac{D_{t}}{P_{t-1}}=R-G,
$$

where $R$ is the long-term discount rate and $G$ is the long-term growth rate of dividends. The Fed model argues that the discount rate on stocks is the yield on bonds plus a proxy for the risk premium of stocks over bonds. These two variables will explain the movement in stock prices if $G$ is constant.

The problem with this interpretation is that the main influence on the long-term nominal interest rate is the expected long-term rate of inflation (Fama 1975, 1990, Mishkin 1990a, 1990b). The long-term real interest rate is comparatively stable and does not move closely with the long-term nominal rate. While the Gordon growth model can be written in nominal terms, this requires that dividend growth $G$ is measured in nominal terms. Since stocks are claims to the productive capital of the real economy, one would expect that a change in long-term expected inflation would move nominal $G$ one-for-one, offsetting the effect on nominal $R$ and leaving the dividend-price ratio unaffected. In real terms, neither $R$ nor $G$ should change with expected inflation. This criticism of the Fed model is forcefully expressed by Asness (2003).

If the above conventional argument does not explain the empirical relation between stock prices and inflation, what does explain this relation? One possibility is that inflation (or the monetary authority's response to inflation) damages the real economy, and particularly the profitability of the corporate sector. In this case real $G$ might fall when inflation rises, justifiably driving up the dividend-price ratio. A variant of this idea reverses the causality, arguing that poor economic prospects induce fiscal and monetary responses that ultimately increase inflation (Geske and Roll 1983). The difficulty with this argument is that $G$ is correctly interpreted as a long-term real dividend growth, not the conditional expected growth at business-cycle horizons such as three years. A second possibility is that inflation makes investors more risk averse, driving up the equity premium and thus the real discount rate $R$. Brandt and Wang (2003) present a model of this effect. 
Modigliani and Cohn (1979) propose a more radical third hypothesis. They claim that stock market investors (but not bond market investors) are subject to inflation illusion. Stock market investors fail to understand the effect of inflation on nominal dividend growth rates and extrapolate historical nominal growth rates even in periods of changing inflation. Thus when inflation rises, bond market participants increase nominal interest rates which are used by stock market participants to discount unchanged expectations of future nominal dividends. The dividend-price ratio moves with the nominal bond yield because stock market investors irrationally fail to adjust the nominal growth rate $G$ to match the nominal discount rate $R$. From the perspective of a rational investor, this implies that stock prices are undervalued when inflation is high, and may become overvalued when inflation falls. The dividend yield that emerges from the interaction of rational and irrational investors is positively correlated with inflation and the long-term nominal interest rate. In recent work, Ritter and Warr (2002) support this idea with a detailed empirical analysis of the 1983-2000 bull market.

In this paper we try to distinguish among these three alternative views. To understand our approach, it is helpful to return to the simple Gordon growth model and subtract the riskless interest rate from both the discount rate and the growth rate of dividends. We define the excess discount rate as $R^{e} \equiv R-R_{f}$ and the excess dividend growth rate as $G^{e} \equiv G-R_{f}$. We are considering the possibility that some investors are irrational, so we must distinguish between the subjective expectations of irrational investors and the objective expectations of rational investors. As long as the irrational investors simply use the present value formula with an erroneous expected growth rate, both sets of expectations must obey the accounting identity of the Gordon growth model. Thus we have

$$
\begin{aligned}
\frac{D}{P} & =R^{e, O B J}-G^{e, O B J}=R^{e, S U B J}-G^{e, S U B J} \\
& =-G^{e, O B J}+R^{e, S U B J}+\left(G^{e, O B J}-G^{e, S U B J}\right) .
\end{aligned}
$$

In words, the dividend yield has three components: (1) the negative of objectively expected excess dividend growth, (2) the subjective risk premium, and (3) a mispricing term that is due to a divergence between the objective (i.e, rational) and subjective (i.e, irrational) growth forecast.

The first step in our analysis is to show that $G^{e, O B J}=R^{e, O B J}-D / P$ tends to rise, not fall, and that $R^{e, S U B J}$ tends to fall, not rise, with inflation, thus ruling out the rational justifications for the comovement of the dividend yield with inflation. 
The second step is to show that, consistent with the Modigliani-Cohn view, high inflation coincides with a positive divergence between objective and subjective growth expectations $G^{e}$, the wedge between the growth expectations of rational investors and irrational investors who are subject to inflation illusion.

\section{Empirical implementation and results}

In our empirical implementation we use the loglinear dynamic valuation framework of Campbell and Shiller (1988), since this framework, unlike the simple Gordon model, allows for time-varying discount rates and dividend growth rates. The Gordon model (1) has the limitation that the expected returns and expected growth must be constant, thus it is suitable for our purposes only as an illustration. The Campbell-Shiller formula for the log dividend-price ratio can be written as

$$
d_{t-1}-p_{t-1} \approx \frac{k}{\rho-1}+\sum_{j=0}^{\infty} \rho^{j} \mathrm{E}_{t-1} r_{t+j}^{e}-\sum_{j=0}^{\infty} \rho^{j} \mathrm{E}_{t-1} \Delta d_{t+j}^{e},
$$

where $\Delta d$ denotes log dividend growth, $r$ denotes log stock return, $\Delta d^{e}$ denotes $\Delta d$ less the log risk-free rate for the period, and $r^{e}$ denotes $r$ less the log risk-free rate for the period. $\rho$ and $k$ are parameters of linearization defined by $\rho \equiv 1 /(1+\exp (\overline{d-p}))$ and $k \equiv-\log (\rho)-(1-\rho) \log (1 / \rho-1)$. A typical value for $\rho$ is 0.97 . When the dividend-price ratio is constant, then $\rho=P /(P+D)$, the ratio of the ex-dividend to the cum-dividend stock price. Comparing Equations (2) and (3), $\sum_{j=0}^{\infty} \rho^{j} \mathrm{E}_{t-1} r_{t+j}^{e}$ is analogous to $R^{e, O B J}$ and $R^{e, S U B J}$, and $\sum_{j=0}^{\infty} \rho^{j} \mathrm{E}_{t-1} \Delta d_{t+j}^{e}$ is analogous to $G^{e, O B J}$ and $G^{e, S U B J}$, depending on whether the expectations taken in Equation (3) are objective (i.e., rational) or subjective (i.e., irrational).

In our empirical work, we will estimate the term $\sum_{j=0}^{\infty} \rho^{j} \mathrm{E}_{t-1}^{O B J} r_{t+j}^{e}$ under objective expectations. The objective expected growth can then be inferred from Equation (3) as $\frac{k}{\rho-1}+\sum_{j=0}^{\infty} \rho^{j} \mathrm{E}_{t-1}^{O B J} r_{t+j}^{e}-\left(d_{t-1}-p_{t-1}\right)$. The subjective risk premium is estimated as the fitted value of a regression of $\sum_{j=0}^{\infty} \rho^{j} \mathrm{E}_{t-1}^{O B J} r_{t+j}^{e}$ on a subjective risk-premium proxy $\lambda_{t}$ (for example, on the relative volatility of stocks vs. that of bonds):

$$
\sum_{j=0}^{\infty} \rho^{j} \mathrm{E}_{t-1}^{O B J} r_{t+j}^{e}=\text { constant }+\gamma \lambda_{t}+\varepsilon_{t}
$$

Mispricing, or the difference between objective and subjective expected dividend growth, is the residual $\varepsilon_{t}$ of this regression. When stocks are subjectively perceived 
to be very risky, then the fitted value $\gamma \lambda_{t}$ is high. In contrast, when stocks are underpriced the residual $\varepsilon_{t}$ is high. Selecting $\gamma$ with a regression implies an assumption that mispricing is independent of the subjective risk premium. This choice for $\gamma$ is in a sense conservative since it minimizes the variance of mispricing.

Following Campbell (1991) and Campbell and Ammer (1993), we combine the valuation framework with a vector autoregression (VAR) that predicts stock returns. The VAR includes the excess log return on S\&P 500 index over the three-month Treasury bill $\left(r^{e}\right)$, the cross-sectional beta premium of Polk, Thompson, and Vuolteenaho $\left(2003, \lambda^{S R C}\right)$, the log dividend-price ratio $(d y)$, and the exponentially smoothed moving average of inflation $(\pi)$. The sample period for the dependent variables is 1927:62002:12, and the sample thus consists of 303 quarterly data points. Table 2 shows the estimated parameters of the VAR system. We use this VAR to infer objective and subjective excess dividend growth and returns.

Table 3 shows the standard deviations and Figure 2 a time-series plot of the three estimated components of the log dividend yield: $-\sum_{j=0}^{\infty} \rho^{j} \mathrm{E}_{t-1}^{O B J} \Delta d_{t+j}^{e}, \gamma \lambda_{t}^{S R C}$, and $\varepsilon_{t}$. Together the three series add up to log-dividend yield. According to Table 3, mispricing is the most volatile component of the log dividend-price ratio, while the subjective risk component is the least volatile. Table 3 also shows the functions that map the four VAR state variables into the three components of the log dividend price ratio. Dividends are expected to grow rapidly when the subjective risk premium and/or inflation is high. Objectively expected excess returns on stocks are high when the subjective risk premium, dividend yield, and/or inflation are high.

Below each number in Table 3 is a standard error, calculated from 10,000 bootstrap simulations of the VAR in Table 2, and an estimate of bias, calculated from the same set of simulations. These standard errors and bias estimates must of course be treated with caution since they are conditional on the validity of the estimated VAR as a description of the data generating process. However, they provide some evidence that the volatility of mispricing, and the effects of inflation on expected dividend growth and mispricing, are statistically significant and are if anything understated by our point estimates.

Perhaps surprisingly, our model detects stock prices significantly overpriced in the summer of 1933, although the dividend-price ratio is approximately at its sample average. This detected overpricing can be explained by two simultaneous phenomena: First, the expected long-run dividend growth was extremely low at 2.5 standard deviations below its sample mean. Second, the subjective risk premium was 1.3 
standard deviations above its unconditional mean. Together, these two facts would have predicted a high dividend yield and low stock prices, contrary to the about average dividend yield observed at the time. Perhaps not surprisingly, another time when stock prices are detected as overpriced is the end of 1999, a point in time many consider the top of the technology bubble. Although at the end of 1999 the subjective risk premium was 0.74 standard deviations below its unconditional mean, expected dividend growth was close to its unconditional mean. The two variables together justify a dividend-price ratio of $3.3 \%$ versus the observed $1.2 \%$, leaving a gap of $2.1 \%$ to be explained by mispricing. At the other end of the spectrum, our VAR detects stock as overpriced in 1947 and 1983, years in which dividend yields weree more than two and half times our fair yield estimates.

The central prediction of the Modigliani-Cohn (1979) hypothesis is that high inflation leads to stock market underpricing and low (or negative) inflation leads to overpricing. The main competing hypotheses are that low stock prices coinciding with high inflation are rationally justified because high inflation coincides with low expected dividend growth or a high subjective risk premium. To examine these hypotheses, we regress the three components of dividend yield on smoothed inflation in Table 3. The regression coefficient of $-\sum_{j=0}^{\infty} \rho^{j} \mathrm{E}_{t-1}^{O B J} \Delta d_{t+j}^{e}$ on inflation is -11.25 with an $R^{2}$ of $95 \%$, implying a positive, not negative, relation between rationally expected excess dividend growth and inflation. To the extent that inflation coincides with poor economic conditions, the worst seems to be over and future growth looks bright (perhaps because of the low initial level). The subjective risk premium seems largely unrelated to inflation. Thus, we reject the rational hypotheses justifying the positive association of dividend yield and inflation.

In contrast, our VAR results in Table 3 provide strong support to the ModiglianiCohn (1979) hypothesis. The regression coefficient of $\varepsilon_{t}$ on inflation is strongly positive, and statistically and economically significant. The strength of this relation is illustrated in Figure 3 that plots mispricing, $\varepsilon_{t}$, and inflation scaled by its regression coefficient, against time. The $78 \% R^{2}$ is evident in the figure as the lines plot almost perfectly on top of each other, as predicted by Modigliani and Cohn.

Table 4 examines the robustness of these results to minor variations in the VAR specification. The first row of the table show the main results from Table 3 as a basis for comparison. Rows two and three alter the data frequency to monthly and annual, with little changes in our main results. Row four uses the relative volatility of stocks vs. bonds as the subjective risk measure, significantly reducing 
the positive correlation between expected excess dividend growth and inflation but actually increasing the $R^{2}$ of inflation on mispricing. Row five substitutes five-year smoothed earnings yield for dividend yield, row six adds the TERM yield spread (the yield difference between long-term and short-term government bonds) to the VAR, and row seven defines excess returns and excess dividend growth rates relative to long-term bond holding-period returns, again with little impact on our main results. Adding three additional lags to our VAR specification adds noise to the estimates; it almost eliminates the positive correlation between dividend growth and inflation, but reduces the $R^{2}$ of inflation on mispricing only to $49 \%$. Finally, row nine accounts for the possibility that the conditional variance of returns may systematically move with the VAR state variables and thus create a time-varying wedge between expected simple and log returns, with no change in results.

\section{Conclusion}

This paper presents a three-way decomposition of the stock market dividend yield into a term due to rationally expected long-run dividend growth, a term due to the subjective risk premium on the market, and a residual term that we attribute to a deviation of subjectively expected dividend growth from objectively expected growth. We use a VAR system to construct empirical estimates of these three components. We find that high inflation is positively correlated with rationally expected long-run real dividend growth; thus the negative effect of inflation on stock prices cannot be explained through this channel. We find that inflation is almost uncorrelated with the subjective risk premium. However, inflation is highly correlated with mispricing, supporting the Modigliani-Cohn (1979) view that investors form subjective growth forecasts by extrapolating past nominal growth rates without adjusting for changes in inflation.

In interpreting this result, it is important to keep in mind that inflation, the stock market dividend yield, and its estimated components are all highly persistent processes. Thus we have relatively few independent observations even in a 75-year history, and our results should be regarded as suggestive rather than decisive. In future work it will be important to gather additional evidence by examining the relation between inflation and stock returns in other countries. It may also be helpful to use survey data to measure subjective inflation expectations. In addition, we cannot rule out the possibility that some part of what we call mispricing is in fact a second component of the subjective risk premium, one that is common to all stocks and thus does not appear in our cross-sectional measure of risk. 
The Modigliani-Cohn hypothesis has interesting implications both for investors and for monetary policymakers. Investors need to know whether stocks, as real assets, provide a hedge against inflation. Fama and Schwert (1977) and others have documented the negative effect of inflation shocks on realized stock returns. The Modigliani-Cohn hypothesis explains this as the result of mispricing driven by inflation illusion, an effect which should diminish over the longer run. Boudoukh and Richardson (1993) examine this issue directly and find that stocks are better inflation hedges over five-year periods than over one-year periods.

There has been an active recent debate about whether monetary policy should be used to combat stock market mispricing. The Modigliani-Cohn hypothesis suggests that disinflation may itself generate mispricing by confusing stock market investors who are subject to inflation illusion. It also implies that a successful stabilization of inflation will reduce the volatility of mispricing and thereby contribute to the efficiency of the stock market. 


\section{References}

Asness, Clifford, 2000, Stocks versus bonds: explaining the equity risk premium, Financial Analysts Journal, March/April 2000, 96-113.

Asness, Clifford, 2003, Fight the Fed model: the relationship between future returns and stock and bond market yields, Journal of Portfolio Management, Fall 2003, $11-24$.

Boudoukh, Jacob and Matthew Richardson, 1993, Stock returns and inflation: A long-horizon perspective, American Economic Review 83, 1346-1355.

Brandt, Michael W. and Kevin Q. Wang, 2003, Time-varying risk aversion and unexpected inflation, Journal of Monetary Economics 50, 1457-1498.

Campbell, John Y., 1991, A variance decomposition for stock returns, Economic Journal 101, 157-179.

Campbell, John Y. and John Ammer, 1993, What moves the stock and bond markets? A variance decomposition for long-term asset returns, Journal of Finance $48,3-37$.

Campbell, John Y. and Robert J. Shiller, 1988, The dividend-price ratio and expectations of future dividends and discount factors, Review of Financial Studies 1, $195-228$.

Fama, Eugene F., 1975, Short-term interest rates as predictors of inflation, American Economic Review 65, 269-282.

Fama, Eugene F., 1990, Term-structure forecasts of interest rates, inflation, and real returns, Journal of Monetary Economics 25, 59-76.

Fama, Eugene F. and G. William Schwert, 1977, Asset returns and inflation, Journal of Financial Economics 5, 115-146.

Geske, Robert and Richard Roll, 1983, The fiscal and monetary linkage between stock returns and inflation, Journal of Finance 38, 1-33.

Gordon, Myron, 1962, The Investment, Financing, and Valuation of the Corporation, Irwin, Homewood, IL. 
Mishkin, Frederic, 1990a, The information in the longer-maturity term structure about future inflation, Quarterly Journal of Economics 105, 815-821.

Mishkin, Frederic, 1990b, What does the term structure tell us about future inflation?, Journal of Monetary Economics 25, 77-95.

Modigliani, Franco and Richard Cohn, 1979, Inflation, rational valuation, and the market, Financial Analysts' Journal.

Polk, Christopher, Samuel Thompson, and Tuomo Vuolteenaho, 2003, New forecasts of the equity premium, unpublished paper, Northwestern University and Harvard University.

Ritter, Jay R. and Richard S. Warr, 2002, The decline of inflation and the bull market of 1982-1999, Journal of Financial and Quantitative Analysis 37, 29-61.

John Burr Williams, 1938, Evaluation by the rule of present worth, The Theory of Investment Value, 55-75. 
Table 1: Explaining the stock yield with a subjective risk-premium measure and nominal bond yield

The table shows the OLS regressions of stock yield (either dividend yield, $D Y$, or smoothed earnings yield where earnings are averaged over the past five years, $5 E Y$ ) on a subjective risk premium measure (either the Spearman rank correlation between firms' valuation multiples and estimated CAPM beta, $\lambda^{S R C}$, or relative past volatility of stocks relative to bonds, $\lambda^{R V}$ ) and on a nominal yield measure (either the ten-year taxable Treasury bond yield, $L T Y$, or smoothed past inflation, $\pi$ ). The t-statistics are computed using Newey-West (1987) standard errors with 60 leads and lags. $R^{2}$ is adjusted for the degrees of freedom. The regressions are estimated from the full sample period 1927:5-2002:12, 908 monthly observations.

\begin{tabular}{|c|c|c|c|c|c|c|c|}
\hline $\begin{array}{l}\text { Stock } \\
\text { yield }\end{array}$ & & Const. & & $\begin{array}{c}\text { Risk } \\
\text { measure }\end{array}$ & & $\begin{array}{c}\text { Nominal } \\
\text { bond yield }\end{array}$ & $\begin{array}{c}\text { adj. } \\
R^{2}\end{array}$ \\
\hline$\overline{D Y_{t}}$ & $=$ & $\begin{array}{r}0.0397 \\
(15.2)\end{array}$ & $\begin{array}{r}+0.0512 \\
(6.4)\end{array}$ & $\overline{c \times \lambda_{t}^{S R C}}$ & $\begin{array}{r}+0.2146 \\
(3.1)\end{array}$ & $\times \pi_{t}$ & $49.2 \%$ \\
\hline $5 E Y_{t}$ & $=$ & $\begin{array}{r}0.0647 \\
(8.2)\end{array}$ & $\begin{array}{r}+0.0684 \\
(3.4)\end{array}$ & $\times \lambda_{t}^{S R C}$ & $\begin{array}{r}+0.2381 \\
(1.2)\end{array}$ & $\times \pi_{t}$ & $27.5 \%$ \\
\hline$D Y_{t}$ & $=$ & $\begin{array}{r}0.0165 \\
(3.4)\end{array}$ & $\begin{array}{r}+0.0029 \\
(5.9)\end{array}$ & $\times \lambda_{t}^{R V}$ & $\begin{array}{r}+0.2156 \\
(2.6)\end{array}$ & $\times \pi_{t}$ & $49.2 \%$ \\
\hline$\overline{D Y_{t}}$ & $=$ & $\begin{array}{r}0.0378 \\
(4.0)\end{array}$ & $\begin{array}{r}+0.0547 \\
(5.2)\end{array}$ & $\times \lambda_{t}^{S R C}$ & $\begin{array}{r}+0.1528 \\
(1.5)\end{array}$ & $\times L T Y_{t}$ & $37.2 \%$ \\
\hline$\overline{D Y_{t}}$ & $=$ & $\begin{array}{r}-0.0069 \\
(-1.0)\end{array}$ & $\begin{array}{r}+0.0046 \\
(6.6)\end{array}$ & $\times \lambda_{t}^{R V}$ & $\begin{array}{r}+0.3576 \\
(5.6)\end{array}$ & $\times L T Y_{t}$ & $49.1 \%$ \\
\hline
\end{tabular}


Table 2: VAR parameter estimates

The table shows the OLS parameter estimates for a first-order VAR model including a constant, the log excess market return $\left(r_{M}^{e}\right)$, the subjective risk-premium measure $\left(\lambda^{S R C}\right), \log$ dividend-price ratio $(d y)$, and smoothed inflation $(\pi)$. Each set of three rows corresponds to a different dependent variable. The first five columns report coefficients on the five explanatory variables, and the last column shows $R^{2}$. Bootstrap standard errors (in parentheses) are computed from 10,000 realizations simulated from the estimated system. The table also reports the correlation matrix of the shocks with shock standard deviations on the diagonal, labeled "corr/std." Sample period for the dependent variables is 1927:6-2002:12, 303 quarterly data points.

\begin{tabular}{lcccccc}
\hline \hline & constant & $r_{M, t}^{e}$ & $\lambda_{t}^{S R C}$ & $d y_{t}$ & $\pi_{t}$ & $R^{2} \%$ \\
\hline \hline$r_{M, t+1}^{e}$ & 0.0768 & -0.0520 & 0.0377 & 0.0190 & 0.1556 & 1.94 \\
& $(0.0902)$ & $(0.0592)$ & $(0.0480)$ & $(0.0266)$ & $(0.4208)$ & \\
\hline$\lambda_{t+1}^{S R C}$ & 0.2501 & 0.0069 & 0.8160 & 0.07653 & -0.6469 & 86.70 \\
& $(0.0612)$ & $(0.0434)$ & $(0.0342)$ & $(0.0180)$ & $(0.2796)$ & \\
\hline$d y_{t+1}$ & -0.1402 & 0.0587 & 0.0087 & 0.9609 & 0.3370 & 92.67 \\
& $(0.0943)$ & $(0.0610)$ & $(0.0496)$ & $(0.0278)$ & $(0.4428)$ & \\
\hline$\pi_{t+1}$ & -0.0036 & 0.0007 & 0.0026 & -0.0012 & 0.9966 & 97.59 \\
& $(0.0039)$ & $(0.0026)$ & $(0.0020)$ & $(0.0011)$ & $(0.0196)$ & \\
\hline \hline corr/std & $r_{M, t+1}^{e}$ & $\lambda_{t+1}^{S R C}$ & $d y_{t+1}$ & $\pi_{t+1}$ & & \\
\hline \hline$r_{M, t+1}^{e}$ & 0.1084 & & & & & \\
$\lambda_{t+1}^{S R C}$ & $(0.0091)$ & & & & & \\
& 0.0227 & 0.0779 & & & & \\
$d y_{t+1}$ & $(0.1143)$ & $(0.0069)$ & & & & \\
& -0.9063 & -0.0132 & 0.1109 & & & \\
$\pi_{t+1}$ & $0.0239)$ & $(0.1082)$ & $(0.0082)$ & & & \\
& 0.1290 & -0.1658 & -0.0983 & 0.0047 & & \\
\hline
\end{tabular}


Table 3: Regressions of dividend yield's components on inflation

The table shows derived statistics implied by the VAR model of Table 2. We decompose the demeaned log dividend yield, $d y_{t}$, into three components: (1) The negative of long-run expected dividend growth, $-\sum_{i=1}^{\infty} \mathrm{E}_{t}^{O B J} \Delta d_{t+1}^{e}$, where $\Delta d_{t+1}^{e}$ is the demeaned dividend growth; (2) the subjective risk-premium component, $\gamma \lambda_{t}^{S R C}$; and (3) the mispricing component. The subjective risk-premium and mispricing components are defined as the fitted values and residuals of the regression $\sum_{i=1}^{\infty} \mathrm{E}_{t}^{O B J} r_{t+1}^{e}=$ $\gamma \lambda_{t}^{S R C}+\varepsilon_{t}$, where $r_{t+1}^{e}$ is the demeaned excess log return on S\&P 500 and $\lambda_{t}^{S R C}$ the demeaned cross-sectional beta premium. The upper-left section of the table, labeled "Stdev" shows the unconditional standard deviations of the three components. The lower left section shows the linear functions that map the VAR state variables into the three components of demeaned log dividend yield. The VAR state variables are the log excess S\&P 500 return $\left(r_{M}^{e}\right)$, the cross-sectional beta premium measure $\left(\lambda^{S R C}\right)$, log dividend-price ratio $(d y)$, and smoothed inflation $(\pi)$. The right half of the table shows the simple regression coefficients of log dividend yield and its three components on smoothed inflation $(\pi)$ and the corresponding regression $R^{2}$ s. Standard errors (in parentheses) and bias estimates [in brackets] are computed from 10,000 simulations from the VAR of Table 2.

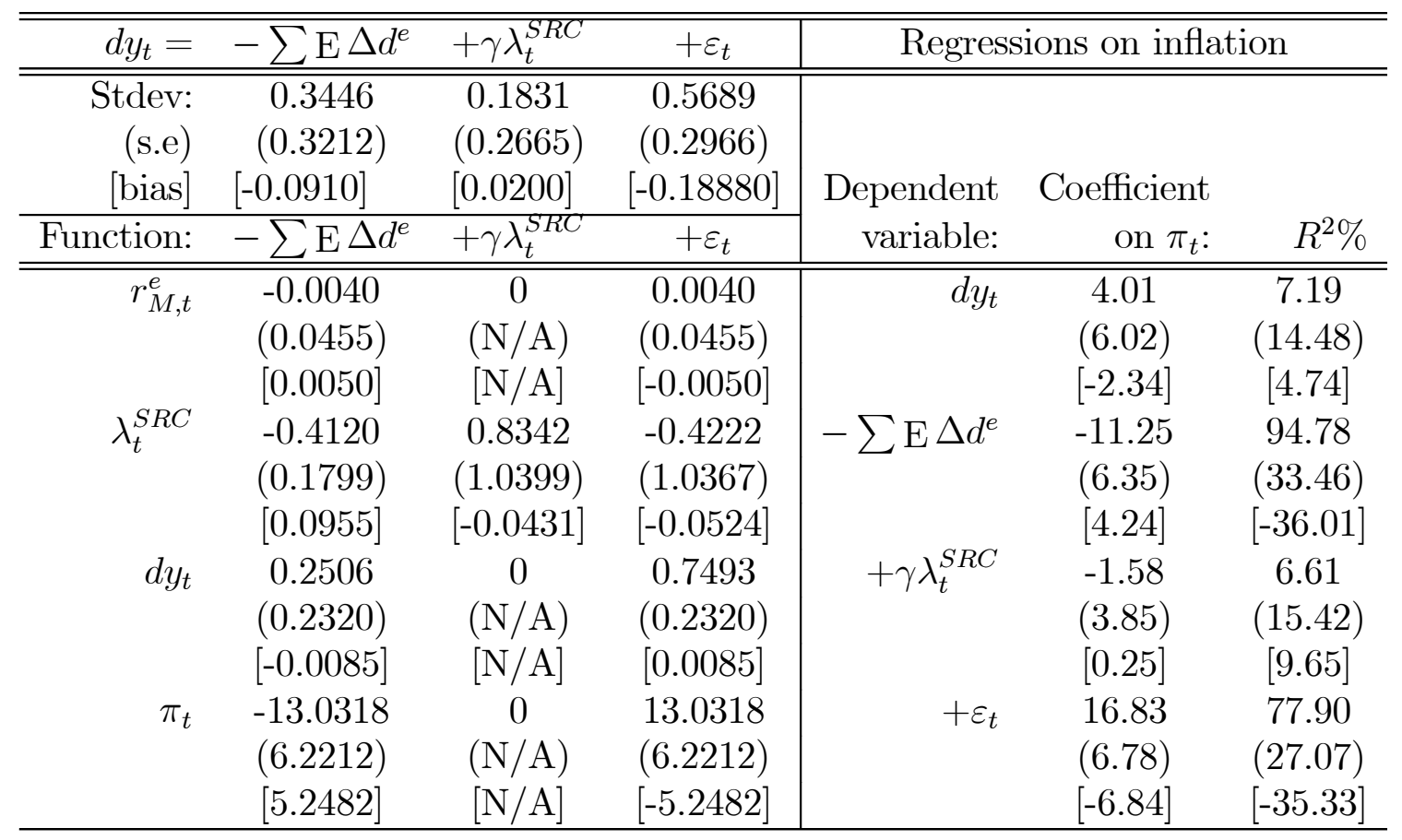


Table 4: Alternative VAR specifications

The table examines the robustness of the implied regression statistics presented in Table 3. In the base specification, we first decompose the demeaned log dividend yield, $d y_{t}$, into three components: (1) The negative of long-run expected dividend growth, $-\sum_{i=1}^{\infty} \mathrm{E}_{t}^{O B J} \Delta d_{t+1}^{e}$, where $\Delta d_{t+1}^{e}$ is the demeaned excess dividend growth; (2) the subjective risk-premium component, $\gamma \lambda_{t}$; and (3) the mispricing component. The subjective risk-premium and mispricing components are defined as the fitted values and residuals of the regression $\sum_{i=1}^{\infty} \mathrm{E}_{t}^{O B J} r_{t+1}^{e}=\gamma \lambda_{t}^{S R C}+\varepsilon_{t}$, where $r_{t+1}^{e}$ is the demeaned excess $\log$ return on S\&P 500 and $\lambda_{t}^{S R C}$ the demeaned cross-sectional beta premium. Then we compute the simple regression coefficients of log dividend yield and its three components on smoothed inflation $(\pi)$ and the corresponding regression $R^{2} \mathrm{~s}$. Each row in the table corresponds to small change in the VAR specification of Tables 2 and 3.

\begin{tabular}{lcccccc} 
VAR specification: & $-\sum \mathrm{E} \Delta d^{e}$ & $R^{2 \%}$ & $+\gamma \lambda_{t}$ & $R^{2 \%}$ & $+\varepsilon_{t}$ & $R^{2 \%}$ \\
\hline \hline 1. Base case & -11.25 & 94.78 & -1.58 & 6.61 & 16.83 & 77.90 \\
2. Monthly data & -11.93 & 92.91 & -1.40 & 7.15 & 17.10 & 80.07 \\
3. Annual data & -6.47 & 67.75 & -3.16 & 10.45 & 12.87 & 64.26 \\
4. $\lambda^{R V}$ instead of $\lambda^{S R C}$ & -0.60 & 0.11 & -4.17 & 2.75 & 10.15 & 82.08 \\
5. 5ey instead of $d y$ & -8.18 & 95.19 & -1.42 & 9.28 & 12.44 & 61.80 \\
6. TERM added & -10.37 & 90.69 & -1.49 & 8.13 & 15.59 & 75.78 \\
7. Stocks - bonds & -14.65 & 96.49 & -1.36 & 6.44 & 20.11 & 82.50 \\
8. Four VAR lags & -0.55 & 1.15 & -3.13 & 10.12 & 7.38 & 48.63 \\
9. Jensens's inequality & -11.31 & 95.22 & -1.07 & 9.35 & 15.26 & 72.52 \\
\hline
\end{tabular}




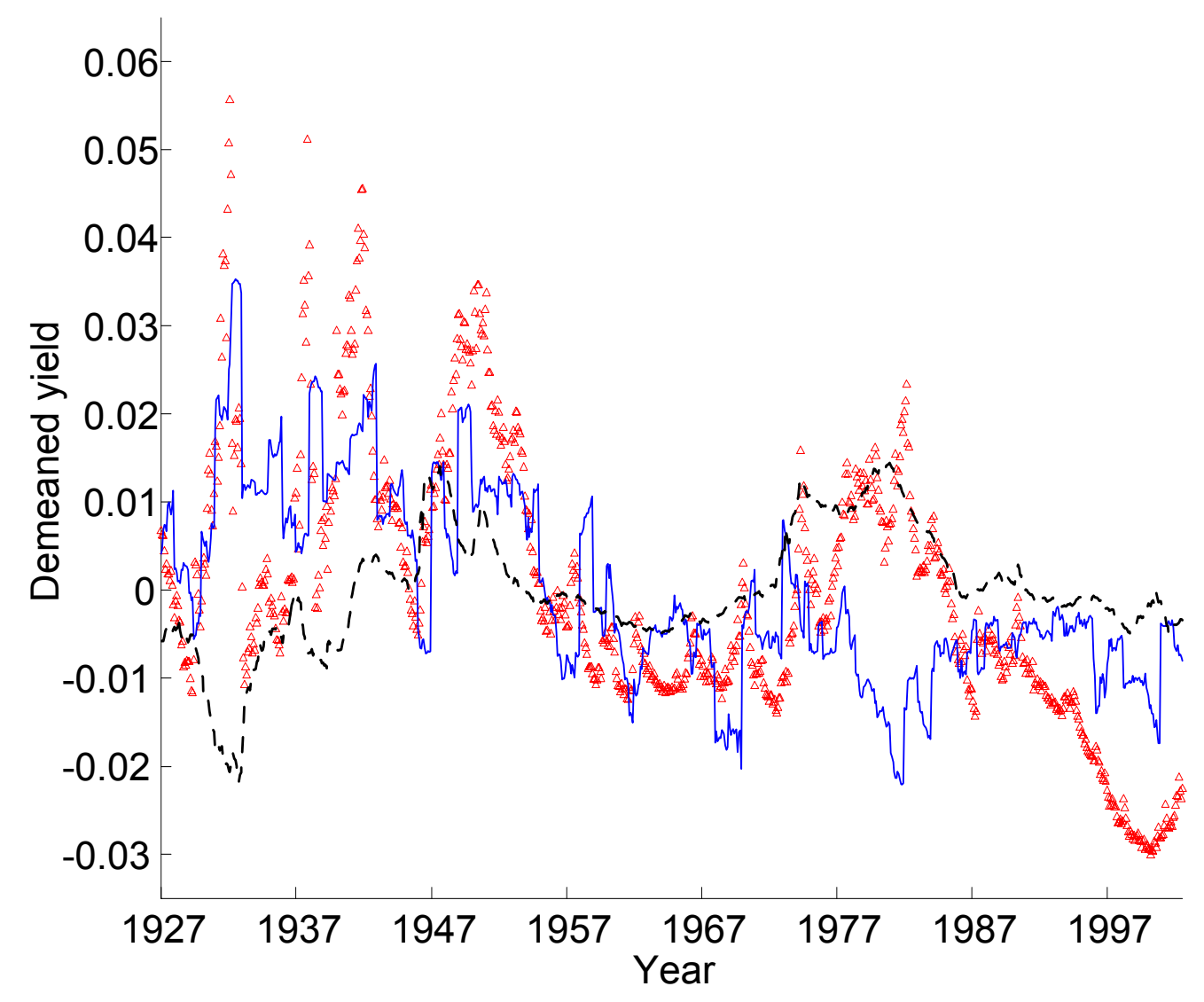

Figure 1: Dividend yield, subjective risk premium, and inflation.

This figure plots the time-series of three variables: (1) Demeaned dividend yield on S\&P 500 index, marked with triangles; (2) demeaned subjective riskpremium measure computed by Polk, Thompson, and Vuolteenaho (2003) as the cross-sectional Spearman rank correlation between firms' valuation levels and estimated betas, marked with a solid line; and (3) the demeaned smoothed inflation computed from the producer price index, marked with a dashed line. Subjective risk premium and inflation are multiplied by their respective multiple regression coefficients in the regression of dividend yield on the subjective risk premium and inflation. The sample period is 1927:5-2002:12. 


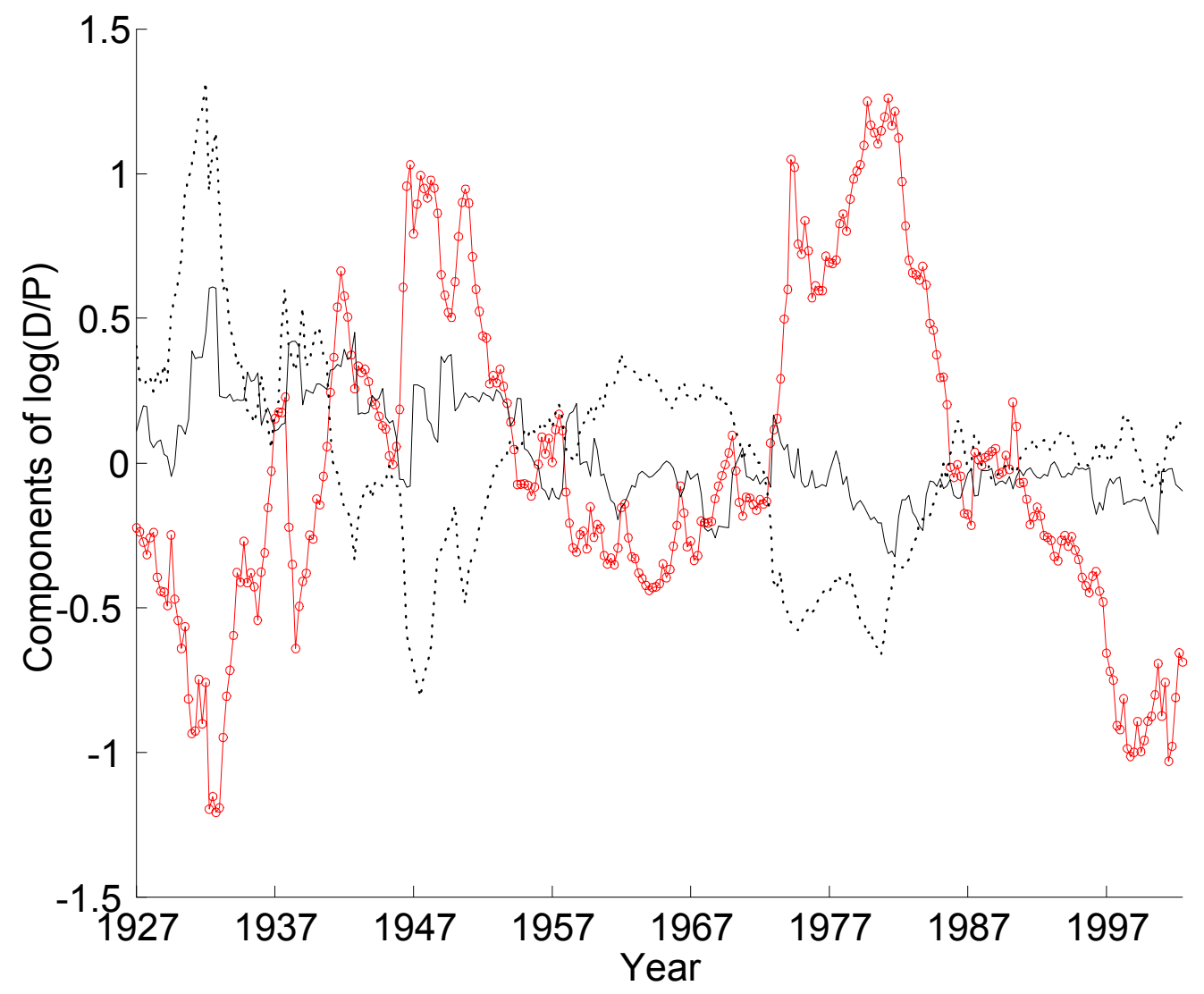

Figure 2: The three components of log dividend yield.

This figure plots the time-series of three variables that add up to demeaned log dividend yield: (1) deviation of the long-run expected excess dividend growth from it's unconditional mean, marked with a dotted line; (2) demeaned subjective risk-premium, marked with a solid line; and (3) the mispricing component, marked with circles and a line. The subjective risk premium component and the mispricing components are produced by regressing the discounted sum of future expected returns on the subjective risk-premium proxy. The subjective risk-premium component is the fitted value of this regression, and the mispricing component is the error term of this regression. The series are computed using the VAR of Table 2. 


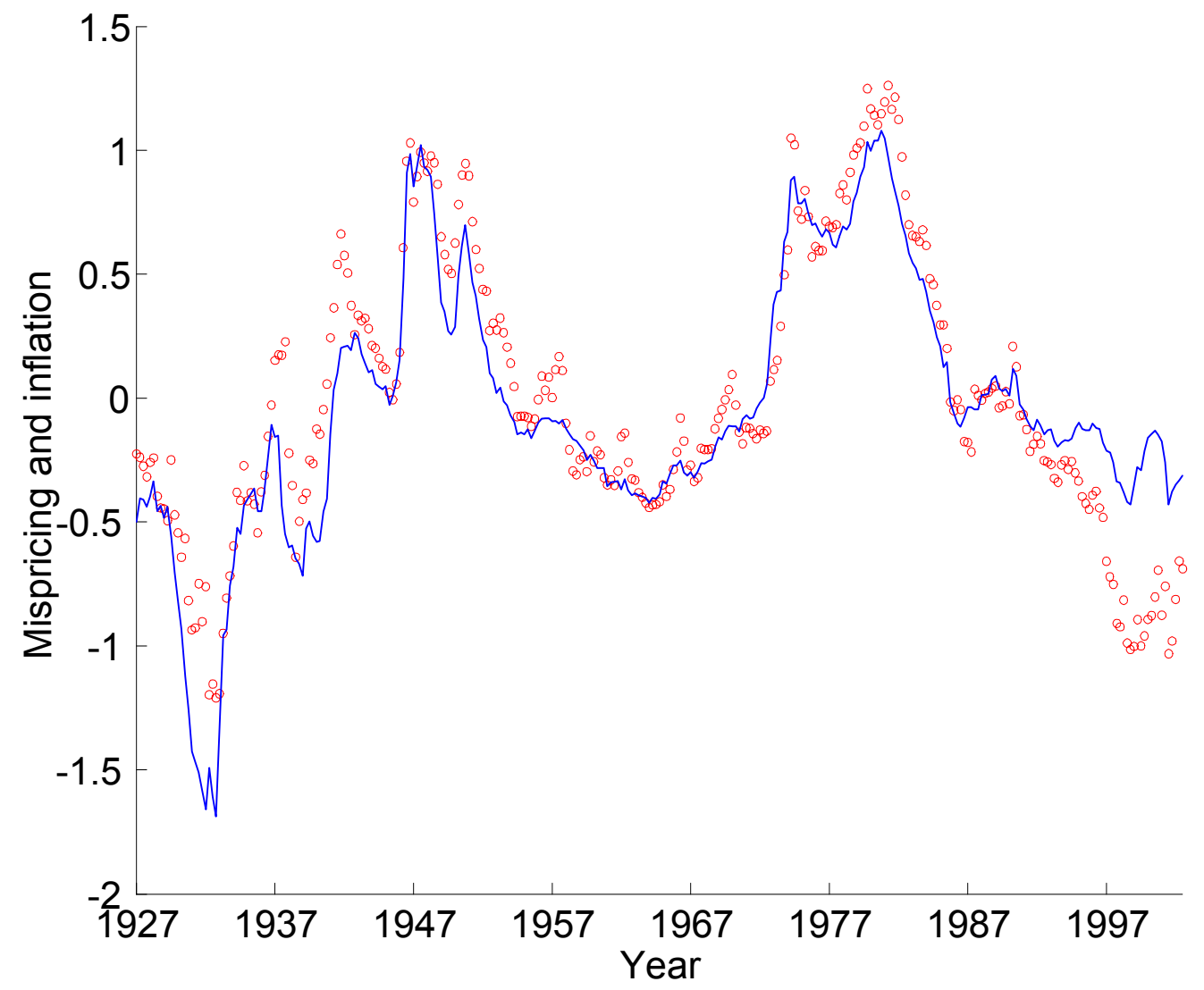

Figure 3: Inflation and mispricing.

This figure plots the time-series of two variables: (1) The mispricing component of $\log$ dividend yield, marked with circles; and (2) the fitted value from a regression of mispricing component on inflation, marked with a line. The mispricing components is produced as the residual of the regression of discounted sum of future expected returns on the subjective risk-premium proxy. The series are computed using the VAR of Table 2. 